\title{
Prevention of Reflux Disease after Operations on Gastric and Intestinal Tract
}

\author{
Martynov V.L, Kolchin D.G, Kurilov V.A, Trukhalev V.A
}

Resident hir. otd. GBUZ BUT "city clinical hospital № 12", Nizhny Novgorod 603033, Nizhny Novgorod, ul. Zaprudnaya, d. 3 , sq. 176. Honeycombs'. Russia

*Corresponding author: Martynov V.L, Resident hir. otd. GBUZ BUT "city clinical hospital № 12", Nizhny Novgorod 603033, Nizhny Novgorod, ul. Zaprudnaya, d. 3, sq. 176. Honeycombs'. Russia

Received date: January 17, 2020; Accepted date: January 28, 2020; Published date: February 07, 2020

Citation: Martynov V.L, Kolchin D.G, Kurilov V.A, Trukhalev V.A,(2020) Prevention of Reflux Disease After Operations On Gastric And Intestinal Tract J. Clinical Medical Reviews and Reports 2(1); DOI: 10.31579/2690-8794/005

Copyright: () 2020 Martynov V, This is an open access article distributed under the Creative Commons Attribution License, which permits unrestricted use, distribution, and reproduction in any medium, provided the original work is properly cited.

\section{Abstract}

Creating anastomoses between the hollow organs of the abdominal cavity, abdominal formations of the retroperitoneal space and the jejunum always raises the question of preventing reflux from the jejunum into the drained cavity of the esophagus, stomach, gallbladder, external hepatic ducts, cysts of the liver and pancreas. After surgery, any reflux becomes pathological. Reflux is an obligate precancer. Thus, the reflux of bile and pancreatic juices in the stomach, the stump of the stomach and esophagus contributes to the occurrence of reflux esophagitis, reflux gastritis, ulcers and gastric cancer or its stump. After internal drainage of the cavity formation in the jejunum, postoperative reflux disease develops, which is caused by the actions of the surgeon who tried to help the patient sincerely. This allowed such states to be defined as "iatrogenic postoperative reflux disease".

The purpose of this work was to develop and introduce into practice the "plug" on the resulting loop of the jejunum, which does not migrate into the lumen of the intestine, with internal drainage of the hollow organs of the abdominal cavity and abdominal formations of the retroperitoneal space and evaluate the clinical results.

As a result, the authors have developed a method for creating a "plug" on the jejunum loop, which is used for drainage, studies are being conducted on its safety, adequacy of functioning, general accessibility, and clinical situations are analyzed. For drainage of the abdominal formation impose a fistula between it and the jejunum loop 40-50 cm from the ligament of Treitz. We form an inter-intestinal fistula according to Brown, above which the length leading to a drained formation of the area of the jejunum is about $10 \mathrm{~cm}$, in the middle of which we impose a "plug". The length of the small intestine section which diverts from the drained formation to the inter-intestinal brown anastomosis is about $30 \mathrm{~cm}$.

To form a "plug", we use the free area of the greater omentum, through which we perform a ligature of non-absorbable polypropylene material by vcol-vykola. The developed method of forming a "plug" does not cause abrupt ischemic changes in the area of operation, followed by necrosis of the intestinal wall and migration of the "plug" into the intestinal lumen, and its effectiveness has been proven using clinical observations, microcirculation studies, water test results and X-ray examination. The method of creating a "stub" is promising for the internal drainage of abdominal cavity formations and retroperitoneal space, for the formation of areflux nutrient eunostoma.

Key Words: surgery, reflux, complications, "plug" on the small intestine.

\section{Introduction:}

Creating anastomoses between the hollow organs of the abdominal cavity, the retroperitoneal space and the jejunum always raises the question of preventing reflux from the jejunum into the drained cavity of the esophagus, stomach, gallbladder, external hepatic ducts, cysts of the liver and pancreas. After surgery, any reflux becomes pathological. Thus, the reflux of bile and pancreatic juices in the stomach, the stump of the stomach and esophagus contributes to the occurrence of reflux esophagitis, reflux gastritis, ulcers and gastric cancer or its stump. Reflux is a precancer [1-3]. The current stage of development of gastric surgery is characterized by a critical assessment of the long-term results of gastrectomy and the search for new, physiological, technical aspects of the operation [4]. The creation of esophago-enteral anastomoses always raises the question of preventing the reflux of intestinal contents into the esophagus. Impact on the mucous membrane of the esophagus of intestinal contents unusual for it, which is possible during gastrectomy and extirpation of the stomach in various modifications, inevitably contributes to the occurrence of reflux esophagitis $[5,6]$. This complication is regarded as severe functional pathology of the operated stomach and occurs, according to different authors, in $19.2-95.4 \%$ of cases $[1,7,8]$.

Most methods of forming an esophageal-intestinal anastomosis are aimed at increasing its reliability and do not provide for the creation of an anti-reflux mechanism that provides physiological, batch evacuation of food $[9,10]$. Prevention of functional impairment after gastrectomy is estimated as an exceptional parameter for improving the quality of life of patients who have undergone an already complicated surgical procedure $[8,11]$. 
During gastrectomy, the inter-intestinal anastomosis during Balfour surgery reduces the incidence $(30-75 \%)$ and the severity of enterogastric reflux compared with those using the Hofmeister - Finsterer method, but does not completely prevent it [12]. In this study, many authors show that the length of the discharge loop of the intestine should be at least $80-100 \mathrm{~cm}$. Only an abdulent segment of the intestine sufficient in length $(80-100 \mathrm{~cm})$ significantly reduces intestinal reflux, which reduces the likelihood of developing ascending cholangitis [3, 13, 14]. At the same time, it is known that in the mobilized along the Roux loop of the small intestine with a length of more than $40 \mathrm{~cm}$ the probability of the development of stasis syndrome sharply increases. Therefore, the length of the discharge loop of more than $40 \mathrm{~cm}$ during resection according to Roux is attributed to the main risk factor for the development of stasis syndrome; a loop length of 35-40 cm is considered optimal [5]. In order to combat these refluxes, Chaput, in 1895 , crossed the lead loop between the anastomoses. To prevent reflux, Y-shaped anastomoses were formed. The most widespread operation in the modification of Ru, but it has its drawbacks: it is necessary to completely cross the intestine, which causes additional infection of the abdominal cavity, microcirculatory changes in the wall of the loop of the intestine, cut out by Roux; the intersection of nerve fibers in $9-50 \%$ of cases causes Ru-staz syndrome $[5,15,16]$.

The number of patients with diseases of the pancreatoduodenal zone, extrahepatic bile ducts, which are accompanied by the development of obstructive jaundice, increases every year [17-19]. The formation of biliodigestive anastomoses causes free communication of the bile ducts with the gastrointestinal tract (GIT), changes the rhythm of bile secretion and creates conditions for ascending infection in the biliary system, leading to the development of reflux cholangitis in $0.7-21.1 \%$ of patients, and scarring formed intestinal anastomoses occurs in $9.8-28.0 \%$ of cases [20-23]. When performing reconstructive operations with an extended or high stricture of the common bile duct, preference is given to biliodigestive anastomoses with the small intestine turned off from the Roux or Brown passage [24-27]. Internal drainage of pancreatic cysts (RV) in the gastrointestinal tract has become the most common, its frequency of use reaches $80 \%$ [28-30, 51]. Of all cystodegative anastomoses, preference is given to the formation of fistula with the jejunum on the disconnected loop according to Roux, Brown or Shalimov [31]. In order to prevent the throwing of intestinal contents in practice, the most commonly used method is the formation of a "stub" proposed by Professor A.A. Shalimov [32, 33], which consists in a laparotomy, the selection of the afferent loop of the small intestine to the drained structure, which is tied up with two ligatures. Instead of ligating the intestine with ligatures, it can be stitched with a lung root suturing clamp (UKL) and then invaginated with sero-serous sutures. However, the authors themselves point to a possible restoration of the patency of the intestinal canal due to the pressure sore of the ligatures. Their invagination also not always can reliably prevent the restoration of the intestinal lumen. A bedsore depends on the ischemia of the intestinal wall in the place where the ligatures or clips of the UCL apparatus are applied.

The imposition of cystopancreatojejunostomy with the intestinal loop not turned off from the passage of the chyme is unacceptable [34]. Creating an anastomosis with the jejunum turned off from the transit of food masses significantly reduces the risk of infection of the cyst cavity [35].

Thus, after internal drainage of the hollow organ into the jejunum when a chyme gets into it, postoperative reflux disease develops, which is caused by the actions of the surgeon who tried to help the patient sincerely. This allowed such states to be defined as "iatrogenic postoperative reflux disease". To prevent bedsores and restore the anatomical patency of the jejunum at the site of imposition of the "plug" should be excluded compression of the tissues of the small intestine.

Creating nutritional eunostomy. The proportion of patients with nutrient enterostomy is $3.3-8.0 \%$ among patients with intestinal ostomy $[32,36]$. Such negative effects of enterostomy as dehydration, electrolyte disturbances, as well as local parastatic manifestations limit the use of this operation. However, the number of patients who need enterostomy formation does not decrease $[37,38]$.

Nutritional eunostoma surgery of the esophagus. Enteral nutrition (EP) has indisputable advantages over parenteral nutrition [39, 40]. The use of enteral nutrition through areflux to an adynamic preoperative period in exhausted patients with prolonged obstruction of the esophagus helps stabilize the body's anabolic processes, restore the visceral and partially somatic pool of proteins, normalize the ratio of protein fractions, improve immune status, thereby more adequately prepare the patient for radical surgery. In the postoperative period, early enteral alimentation contributes to a more rapid activation of intestinal motility, reduces the number of infectious complications [39-41].

Tumor stenoses and cicatricial strictures of the esophagus lead to obstruction of the proximal digestive tract with the development of alimentary insufficiency, exhaustion and extinction of the compensatory abilities of the body [42], which causes the rejection of the simultaneous formation of an artificial esophagus in patients of this category.

Conducting EP through the areflux valve valve in patients with cancerous stenosis of the esophagus can be the method of choice for preoperative preparation and postoperative management [43]. Enteral nutrition through areflux enostomy has all the advantages of parenteral, has fewer complications. In addition, areflux valve eunostoma allows not only to feed the patient, but also to keep the stomach suitable for further plastics [42]

Nutritional eunostoma in gastric surgery. V.D. Fedorov (2008) reported five observations of patients [44] who, due to continued bleeding after conservative treatment, endoscopic and a number of surgical interventions (gastrotomies with suturing erosions and ulcers, resections and resections of the stomach) against the background of deep anemia and hypoproteinemia were forced extirpation of the stomach stump was made. Due to the severity of the condition of the patients, the operations were limited to the removal of the gastric stump without the imposition of esophagoenterostomy. These operations were completed by external drainage of the abdominal segment of the esophagus and the imposition of Yeunostoma according to Maidl for subsequent enteral feeding. Thanks to intensive treatment, three out of five patients survived. After 4-6 months, he performed reconstructive surgeries with imposition of the esophago-intestinal anastomosis along Roux.

The most effective method of treating patients with duodenal stump failure is the drainage of the stump area in combination with enteral tube feeding [45]. The use of the Y-shaped eynostoma for thesepurposes made it possible to reduce mortality by 2 times.

Nutritional eunostoma in biliopancreatoduodenal surgery. Oncological diseases of the biliopancreatoduodenal zone account for 
$3.6 \%$ of the total oncological structure and reach $11.5 \%$ among the malignant neoplasms of the gastrointestinal tract with a frequency of involvement in the pathological process of the pancreas, reaching 63 $86 \%[6,34]$.

Pancreatoduodenal resection is the main method of radical surgical treatment of tumors of the pancreas, but is accompanied by the development of severe postoperative complications [46], the most frequent of which are the divergence of the sutures of the pancreatojejunal anastomosis, the development of acute postoperative pancreatitis, multiple organ failure; mortality reaches $50 \%$ [13, 47, 48].

Nutritional eunostoma in mediasthenitis surgery. The problem of increasing the efficiency of treatment results in patients with acute perforation mediastinitis for many years remains an urgent task [50].

I.V. Yurgelas (2009) found that jejunostomy provides antireflux protection, enteral nutrition, gastrointestinal decompression and treatment of intestinal insufficiency syndrome and in the complex treatment of acute perforation mediastinitis allows for 3.72 times lower mortality rates, the frequency of registration of both isolated complications and the development of their complex combinations [48].

The purpose of the study is to develop and introduce into practice the "plug" on the resulting loop of the small intestine, which does not migrate into the intestinal lumen, with internal drainage of the hollow organs of the abdominal cavity and abdominal formations in the retroperitoneal space.

\section{Material and methods:}

For drainage of the abdominal mass, a fistula is placed between it and the jejunum loop 40-50 $\mathrm{cm}$ away from the Treitz ligament. Form interintestinal fistula according to Brown. The length leading to the drained formation of the jejunum area from the inter-intestinal anastomosis is about $10 \mathrm{~cm}$, in the middle of which a "cap" is placed. The length of the region of the jejunum which diverts from the drained formation to the inter-intestinal Brownian anastomosis is about $30 \mathrm{~cm}$ (Fig. 1).

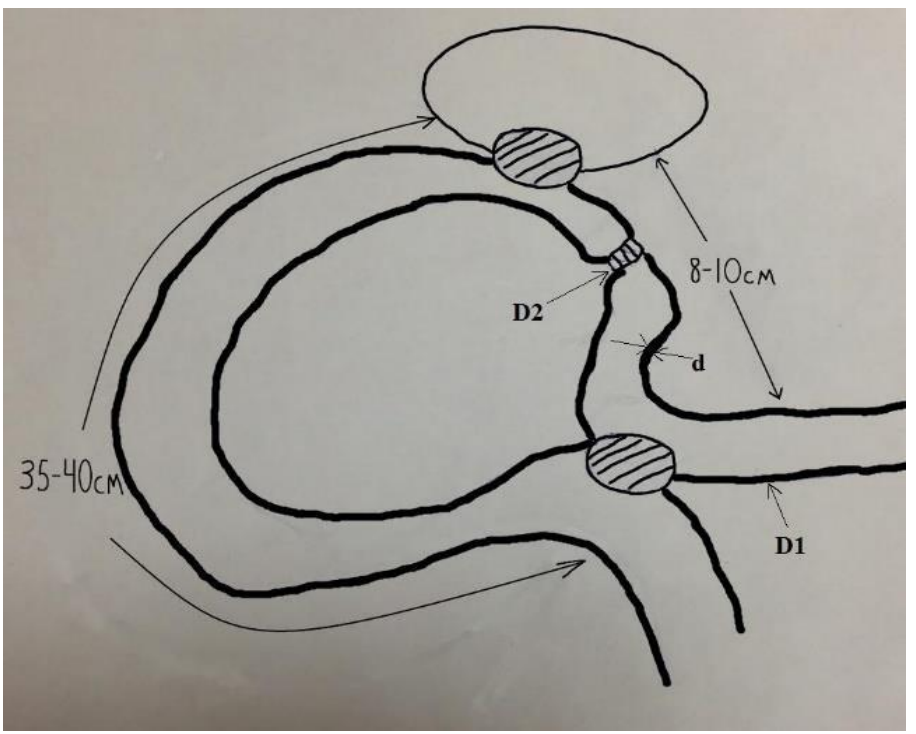

Development of the formula for the diameter of the "plug" in the small intestine

We form a "plug" on the small intestine according to the developed method, in which compression and necrosis of the small wall are excluded, followed by migration of the "plug" into the intestinal lumen. As can be seen from the operation scheme, the principle of drainage according to Roux remains, but without crossing the intestine, nerve pacemaker fibers (there is no threat to the development of Roustaz syndrome), without additional infection of the abdominal cavity (Fig. 1 $\mathrm{A}, \mathrm{B}, \mathrm{C})$.

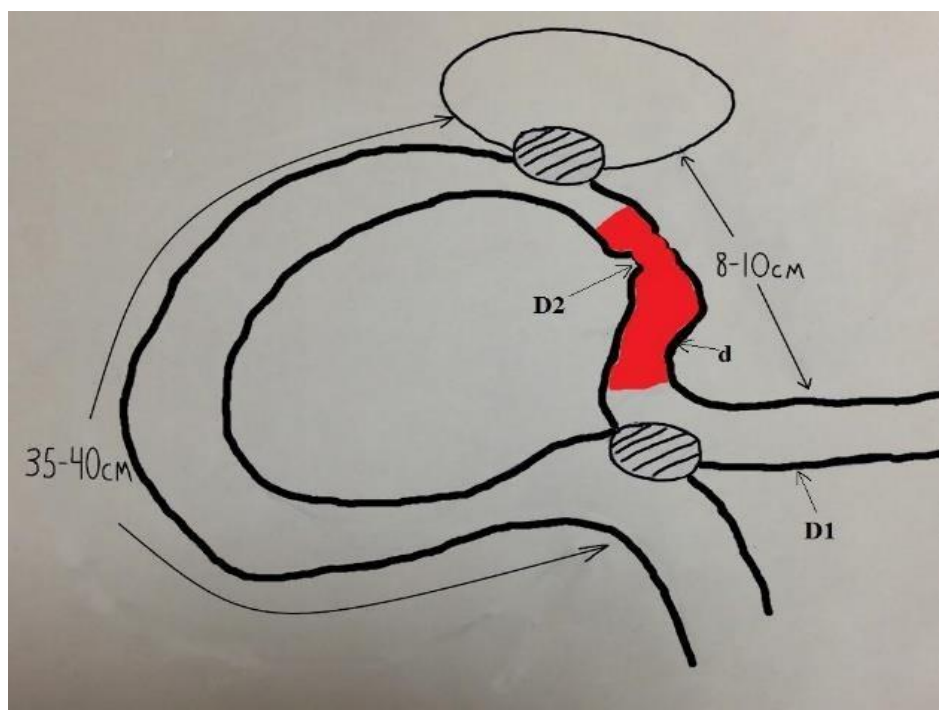

Figure. 1-A. Scheme of drainage abdominal cavity formation

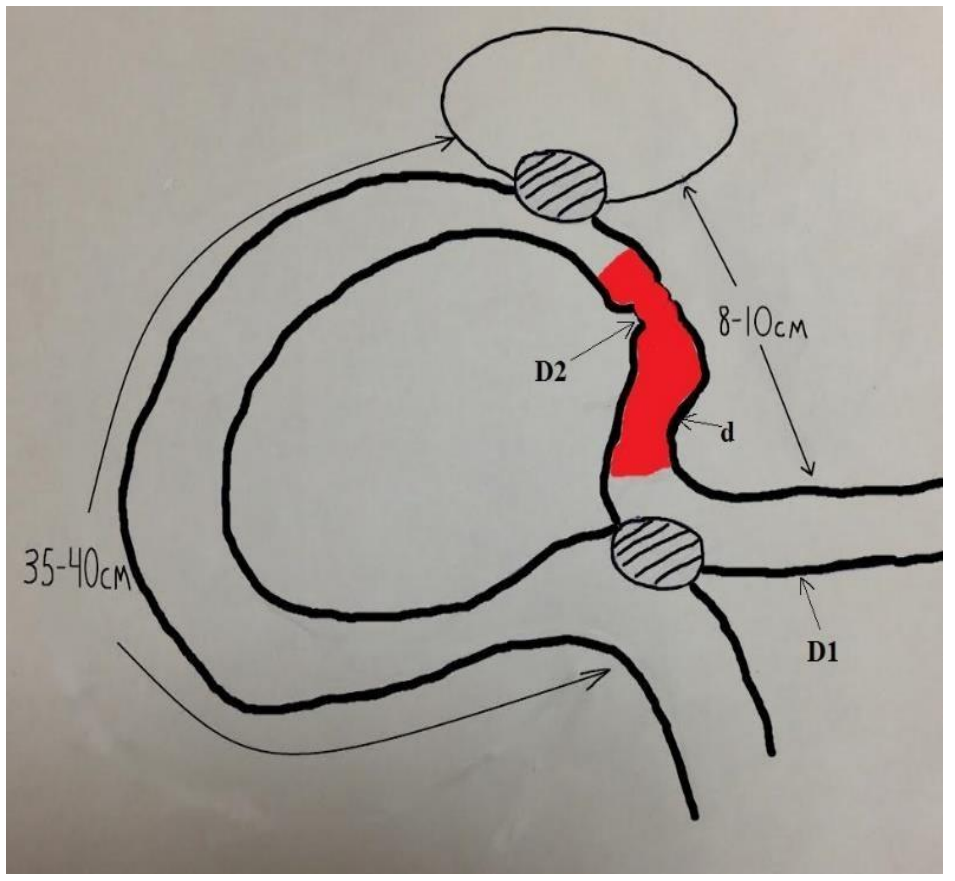

Figure. 1-B. The small intestine, which does not miss the chime

\section{Figure 1}




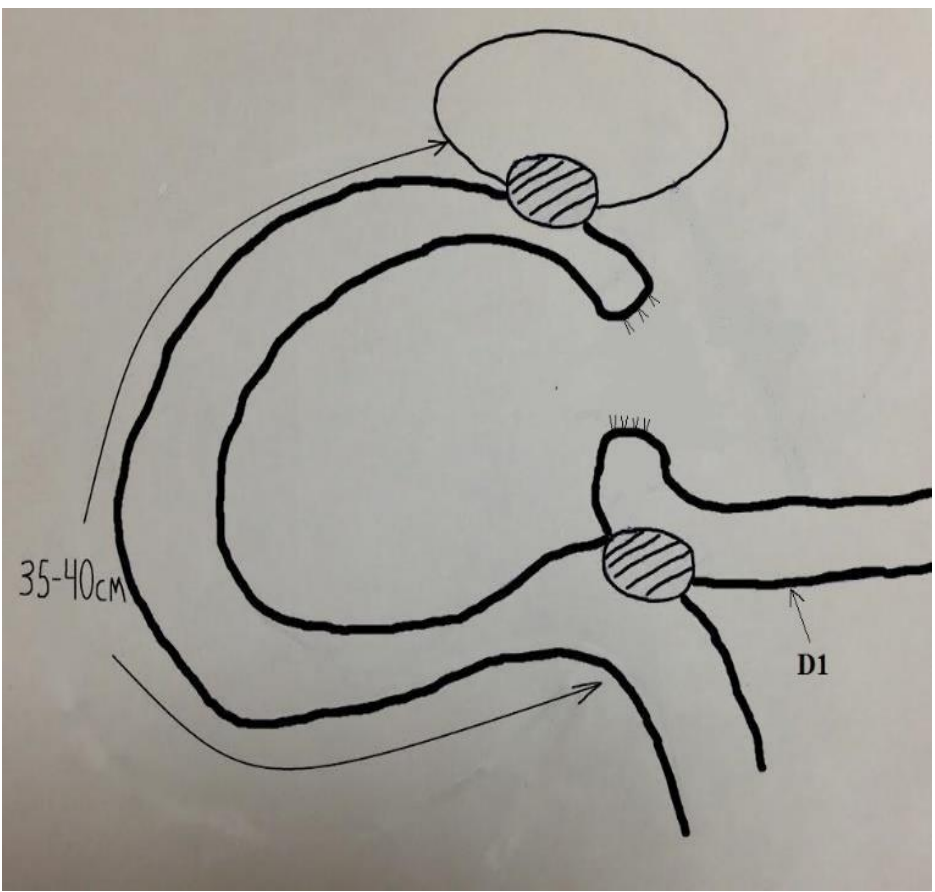

Figure. 1-C. mentally removed part of the intestine that does not allow chyme - a variant of the drainage technique according to $\mathrm{Ru}$

For the formation of the "plug", a free area of the greater omentum is used, through which a ligature of non-absorbable polypropylene material is carried out by vcol-vykola (Fig. 2).

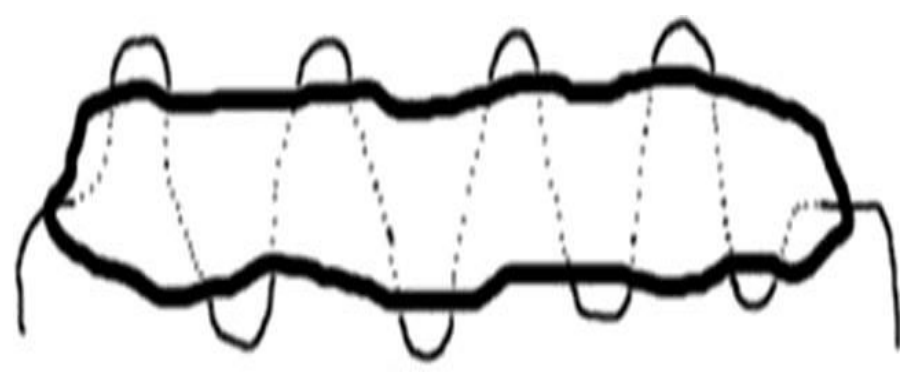

Figure. 2. Scheme of construction "stub". Plot large omentum with held through it non-absorbable ligature.

To exclude reflux, a $2-5 \mathrm{~cm}$ distal to the intestinal anastomosis from the afferent loop is $2-5 \mathrm{~cm}$ distal to the intestinal fistula and a "plug" is applied according to the developed procedure, in which compression and necrosis of the small intestine wall are excluded (RF patent No. 2253379) with subsequent migration of the "plug" into the lumen of the intestine (Fig. 3).
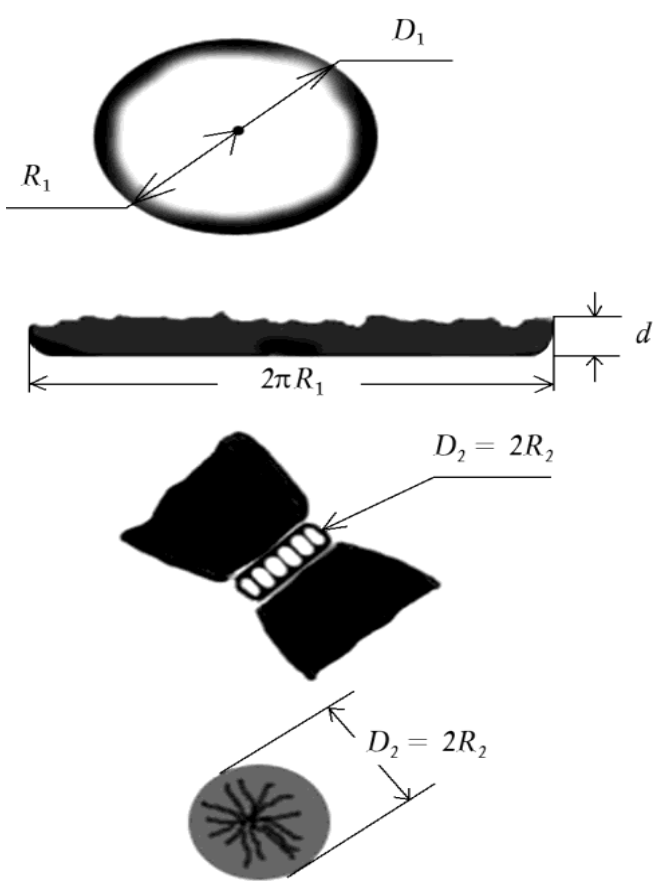

Figure. 3. Diagram of a mathematical model of the formation of a "plug" on the wall of the jejunum of the afferent loop. The diameter of the "plug" is determined by the wall thickness and the diameter of the jejunum

For the imposition of "plugs" by the developed method during the operation, the caliper of the jejunum wall $\mathrm{d}$ is determined by a caliper (divided into 2 thickness of the matched opposite walls) and the diameter of the section of the small intestine D1, on which the "plug" is planned. Upon receipt of the desired parameters, the required diameter of the "plug" is calculated, and thus the corrugated portion of the jejunum is calculated using the formula D2 $=2 \mid \mathrm{D} 1 \mathrm{~d}$, after which the intended operation stage is performed (RF patent №2253379): $d$ is the thickness of the jejunum wall; R1 is the radius of the small intestine; $\mathrm{R} 2$ is the radius of the corrugated portion of the small intestine; D1 is the diameter of the jejunum; D2 is the diameter of the corrugated section of the small intestine by a "stub"; $\mathrm{S} 1=2 \pi \mathrm{R} 1$ - the cross-sectional area of the wall of the small intestine; $\mathrm{S} 1=2 \pi \mathrm{R} 1 \mathrm{~d}=\mathrm{D} 1 \pi \mathrm{d} ; \mathrm{S} 2=\pi \mathrm{R} 22=\pi(\mathrm{D} 2 / 2) 2-$ the crosssectional area of the corrugated wall of the small intestine; S1 = S2 - the condition of the absence of compression, ischemia and necrosis of the wall of the small intestine in the area of "stub"; D1 $\pi d=\pi(D 2 / 2) 2$; 2 / 2 = D1d. The construction of the "plug" is formed from a free insulated section of the greater omentum, through which a ligature of nonabsorbable polypropylene material is drawn by injecting a stick. This complex is placed on the small intestine, the ends of the thread are tied with the formation of a ring with a diameter of D2. 
The obtained possible intraoperative values of the wall thickness of the small intestine, its diameter and the obtained required diameter of the "plug" according to the formula (RF Patent No. 2253379 (authors
Martynov V.L., Kolchin D.G., Buldakov D.I. , Bodrov AA)) are combined in a table (Table 1).

\begin{tabular}{|c|c|c|c|c|}
\hline \multirow{2}{*}{$\begin{array}{c}\text { Diameter wall } \\
\text { thickness, cm }\end{array}$} & \multicolumn{5}{|c|}{ Required diameter of the "plug", cm } \\
\cline { 2 - 5 } & 0,2 & 0,3 & 0,4 & 0,5 \\
\hline 3 & 0,68 & 1,02 & 1,4 & 1,7 \\
\hline 3,5 & 0,76 & 1,12 & 1,5 & 1,87 \\
\hline 4 & 0,8 & 1,2 & 1,6 & 2 \\
\hline 4,5 & 0,84 & 1,26 & 1,7 & 2,1 \\
\hline 5 & 0,88 & 1,32 & & 2,2 \\
\hline
\end{tabular}

Table 1: Determination of the required diameter of the "plug" on the adductor loop of the small intestine during internal drainage of abdominal cavity and retroperitoneal cavities.

Using the developed table, it is not necessary to spend time on mathematical calculations. After measuring the wall thickness of the jejunum and its diameter, comparing the results, we find in the table the required diameter of the "plug" and form it surgically in accordance with the size found.

\section{Determination of the state of the microcirculatory bed of the intestinal wall of the "plug" zone in the experiment}

The evaluation of microhemodynamics with various methods of forming an intestinal anastomosis was carried out by laser Doppler flowmetry on the LAKK-02 apparatus (NPP Lazma, Russia) in an experiment on 10 white-down rabbits (age 1.5-2.0 years), which were formed by three "plugs" on the jejunum: two ligatures (the first) and the apparatus of the UKL according to A.A. Shalimov (the second) and the developed method (the third).

Water sample. The study was performed on 15 anatomical preparations, then - on 15 rabbits. According to the developed formula with the use of a non-absorbable ligature and the free strand of the greater omentum, a "plug" was placed on the small intestine with the calculation of the absence of ischemia of the intestinal wall. At $10-15 \mathrm{~cm}$ from the "plug", a soft intestinal press was applied. Between the pulp and the "plug" created a closed space. Water was injected into the lumen of the intestine between the "plug" and the clamp through a needle until the voltage of this section of the intestine was significant, and the possible passage of water through the "plug" zone was evaluated.

$\mathrm{X}$-ray examination. In the immediate postoperative period, fluoroscopy of the anastomosis area with passing barium was performed with normal radiographs (see Figs. 5, 6) to normalize the condition. The study was performed in $57(83 \%)$ patients.

The clinical application of the method was carried out in the surgical department of the State Budgetary Healthcare Institution "GKB No. 12 of Nizhny Novgorod" The criteria for inclusion in the study group were the formation of a "plug" on the jejunum during the drainage of the hollow organs of the abdominal cavity and abdominal formations of the abdominal space in various pathologies. The study group consisted of 155 patients aged from 20 to 78 years. Among them were 53 (34\%) men and 102 women $(66 \%)$.
The nature of the diseases for which patients are operated to drain cavities with the formation of a "plug": pancreatic cysts - 15 , stomach cancer - 13, chronic violation of duodenal permeability - 92, liver cysts - 2, pancreatic head cancer, mechanical jaundice - 21, Vater papilla cancer, obstructive jaundice - 10, strictures of extrahepatic bile ducts -7 , rupture of the lower thoracic esophagus, mediastinitis - 1, pancreatic cancer and stomach with high obstruction, which required the position of nutritious areflux yeunostomy - 4 .

During examination in the clinic, patients were diagnosed with comorbidities (for a number - combined comorbidities): bronchial asthma - in 52, diabetes mellitus - in 5, urological and gynecological pathology (urolithiasis, chronic adnexitis) - in 3, hypertensive disease and CHD - in 4 , vegetative dystonia syndrome - in 39 , chronic tonsillitis and pharyngitis - in 37 , peptic ulcer of the stomach and duodenum - in 51, chronic calculous cholecystitis - in 20 , chronic colic stasis - in 12 , rheumatoid arthritis $\mathrm{t}$ - at 3, skin disease (psoriasis, neurodermatitis, eczema) - at 36 .

This procedure was used in the following operations: in 15 cases - in the drainage of pancreatic cysts, in 5 - in the case of gastroenterostomy, in 5 - in the case of gastroenterostomy after gastrectomy, in 3 - in the case of esophagiojejunostomy after gastrectomy, in 92 - with duodenojejoneostomy, in 2 - with drainage of liver cysts, in 21 - with cholecystojejunostomy, in 7 - with reconstructive operations on the biliary tract, in 1 - with the imposition of a "plug" on the cervical esophagus (instead of ligation) with its perforation and development of mediasthenitis, in 4 - for the formation of ares luxurious nutritional stoma.

\section{Results}

Clinical observations: The duration of observation of the operated patients was from 1 to 5 years. In no case was the migration of the created construct into the lumen of the intestine or specific complications noted. In five cases, after repeated relaparotomy for other diseases, the formed structure adequately fulfilled its functions, being the system that was originally created, while in five clinical observations (the operation to create a "plug" modified by AA Shalimov was carried out in other medical institutions ) "Plug", created using the UKL apparatus, was not found in the places of its formation and isolation of the drained cavitary formation was not achieved. 


\section{Microcirculation study:}

In the area of "plug - gland with a ligature" microcirculation (MC) decreased by $10.3 \%$. In the area of "plug - UKL" between the lines of clips MC was absent. In the area of "plug - ligatures" MC between the threads was also absent. That is, there is a great risk of necrosis of the intestinal wall between the lines of the clips and between the ligatures with possible dangerous consequences. In $1 \mathrm{~mm}$ aside from the line of formation of the "plug - UKL" of the MC decreased by $17.9 \%$, in $1 \mathrm{~mm}$ of the "plug of the ligature" of the MC decreased by $14.1 \%$. In the zone of each "stub" marked venular stasis. In the "stub" zone with an epiploon, all compensatory mechanisms for the normalization of the MCs were activated (Table 2).

\section{Results of water test:}

In no case did the passage of water through the zone of the formed "plug", both in the experiment and in all 155 clinical intraoperative studies, were noted (Fig. 4)

The results of x-ray examination. In no case was the flow of barium into the drained structure. The contrast stopped in front of the "plug", which was guaranteed not to let intestinal contents through this intestinal segment.

\begin{tabular}{|c|c|c|c|c|c|c|c|}
\hline Indicator & $\begin{array}{l}\text { Original } \\
\text { (before the } \\
\text { imposition } \\
\text { of "plugs") }\end{array}$ & $\begin{array}{l}\text { The resulting value } \\
\text { ("plug - gland") }\end{array}$ & $\Delta, \%$ & $\begin{array}{l}\text { The resulting value } \\
\text { ("stub - UKL") }\end{array}$ & $\Delta, \%$ & $\begin{array}{l}\text { The resulting value } \\
\text { ("stub - } 2 \\
\text { ligatures") }\end{array}$ & $\Delta, \%$ \\
\hline $\bar{M}$ & 78 & 70 & $-10,3$ & 64,0 & $-17,9$ & 67,0 & $-14,1$ \\
\hline$\delta$ & 9,2 & 9,6 & 4,3 & 8,7 & $-5,4$ & 7,8 & $-15,2$ \\
\hline AmaxC & 5,9 & 6,8 & 15,3 & 12,2 & 106,8 & 6,3 & 6,8 \\
\hline АmaxД & 7,1 & 8,8 & 23,9 & 10,2 & 43,7 & 8,6 & 21,1 \\
\hline AmaxM & 8,8 & 10,7 & 21,6 & 10,5 & 19,3 & 9,4 & 6,8 \\
\hline AmaxH & 5,6 & 6,5 & 16,1 & 16,0 & 185,7 & 11,1 & 98,2 \\
\hline ПШ & 1,48 & 0,62 & $-58,1$ & 1,53 & 3,4 & 1,19 & $-19,6$ \\
\hline
\end{tabular}

Table 2: Indicators of microcirculation zones of different ways of the formation of "plugs"Indicator Initial (before imposition of "plugs")

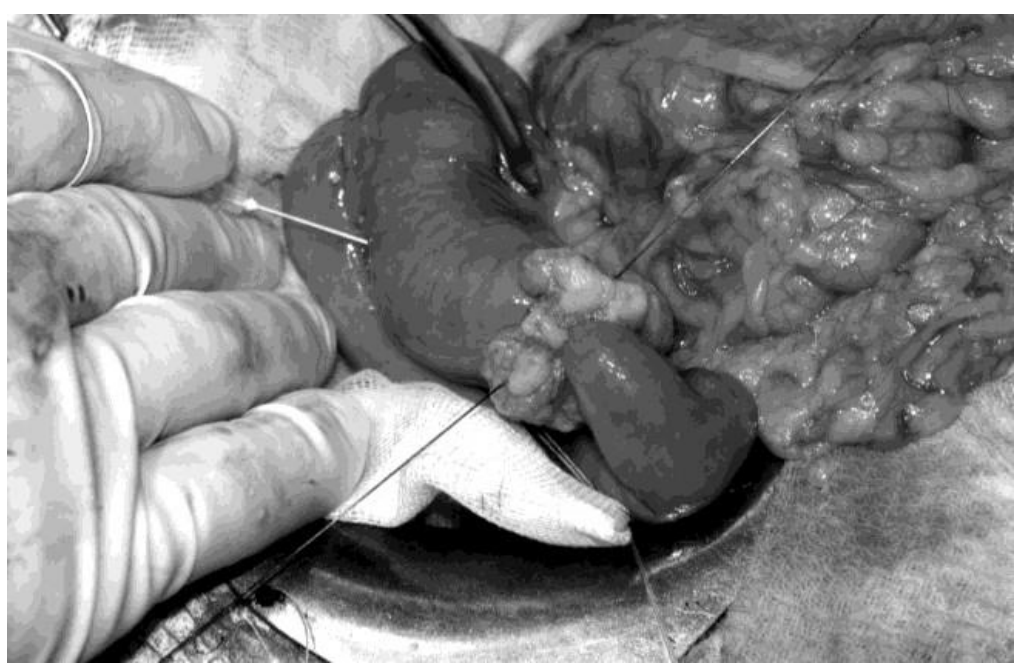

Figure. 4. Intraoperative water sample. Water does not pass through the stub zone.

We give an example of the clinical functioning of the "plug" on the jejunum adductor loop to the esophagus after gastrectomy. On a series of $\mathrm{X}$-ray images, no barium passage through the jejunum segment in the place of the formed "plug" was detected. The contrast goes to the leading part of the jejunum only to the "stub" zone. The main part of the contrast goes through the outlet gut (Fig. 5, 6). Thus, it has been proven that the esophagus is isolated from the damaging effects of bile, the digestive juices of the duodenum and the pancreas. 


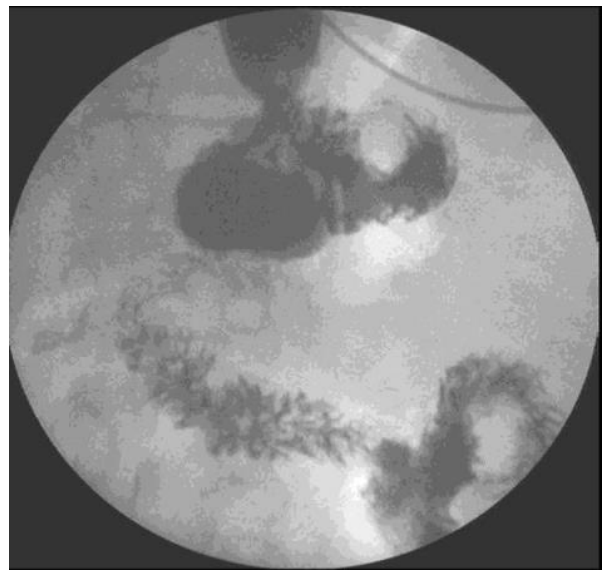

Figure. 5. Roentgenogram of the esophagic region. Barium reaches the zone of the stub of the adductor department, without penetrating it, passes through the abductor from the esophagojejunostomy through the loop of the jejunum.

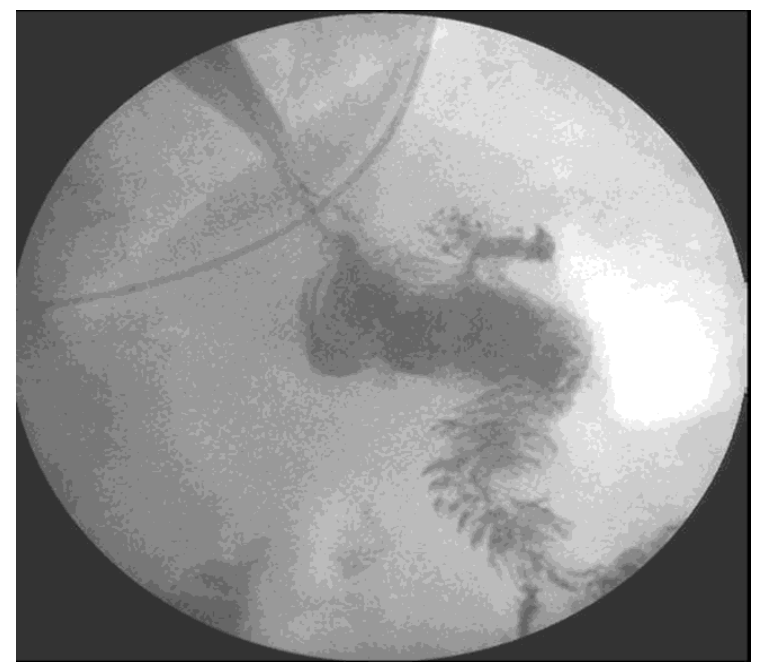

Figure. 6. Roentgenogram of the esophagic region. After a few seconds, the barium in the bulk left the zone of the esophago-intestinal anastomosis, does not pass through the zone of the "plug"

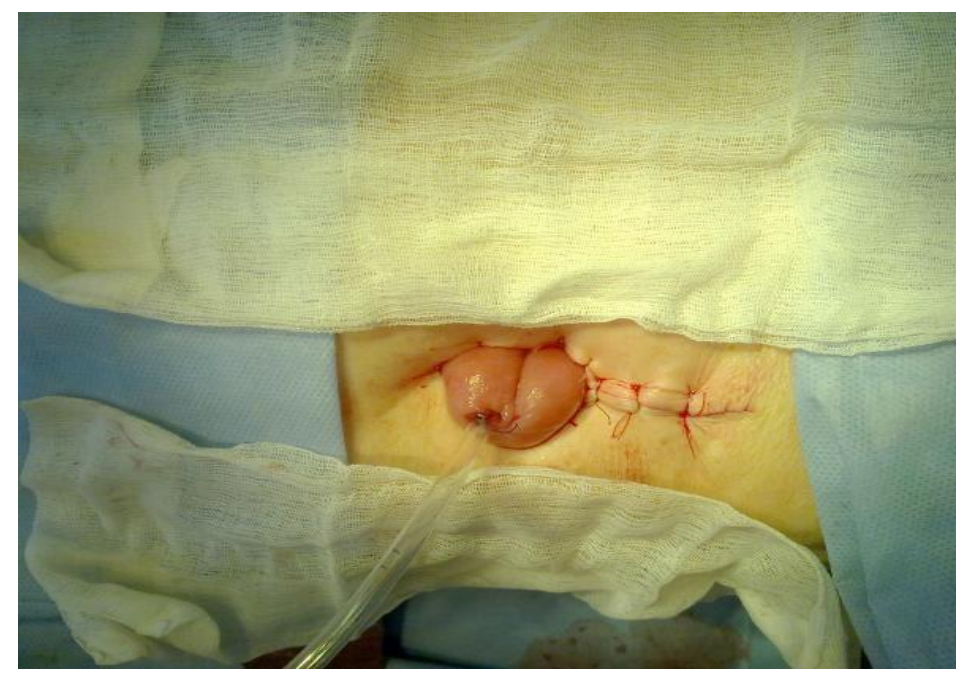

Figure 7. Areflux nutrient eunostom. The free part of the loop of the small intestine is brought to the skin for the purpose of enteral nutrition. An inter-intestinal brown anastomosis is provided with a nourishing probe.

\section{Findings}

1. The developed method of forming a "plug" does not cause abrupt ischemic changes in the area of operation, followed by necrosis of the intestinal wall and migration of the "plug" into the intestinal lumen.

2. The formed "plug" according to the developed method in practice does not guarantee that the chyme passes through this intestinal segment.

3. The method is safe, widely available, adequately performs the intended areflux function.

4. The method of creating a "stub" is promising for the internal drainage of the hollow organs of the abdominal cavity and abdominal formations of the retroperitoneal space, for the formation of areflux nutritional ejunostoma.

\section{References}

1. Kotiv B.N, Pryadko A.S, Luft A.V. (2012) Combined surgical treatment of peptic strictures of the esophagus in patients with gastroesophageal reflux disease // Surgery.(1) 29-33.

2. Onopriev V.I, Uvarov I.V. (2004) Gastrectomy with conceptual endopathy at gastric cancer // Surgery.(9) 32-36.

3. Onopriev V.I, Manuilov A.M.(1995) Is it time to eliminate the contradiction? // Abstracts of the reports of the VIII All-Russian Congress of Surgeons. Krasnodar. 201-203.

4. Davydov M.I, Ter-Ovanesov I.S. (2002) Modern strategy of surgical treatment of gastric cancer // Vesti Grew. Acad. honey. Sciences. (1) 25-29.

5. Gibadulin N.V, Gibadulina I.O. (2011) Reconstruction of esophageal-intestinal anastomoses according to Roux as a method of surgical correction of postgastrectomy and postgastrectomy syndromes // Surgery.(11) P. 32-36.

6. World Cancer Report. 2008. 530 r.

7. Zherlov G.K.(2001) Functional results of the operation of the formation of an "artificial stomach" after gastrectomy and subtotal gastrectomy // Herald of Surgery. 160 (4) 22-26.

8. Tazhibaev M.K.(2009) Prompt and technical prevention of postgastrectomy reflux esophagitis: dis. Cand. honey. sciences. Bishkek,113 p.

9. Zinoviev D.Yu., Sergeev I.V. Immediate results after gastrectomy // Works scientific and practical. conf. Penza, 2003. T. 1 (section 2). Pp. 19-23.

10. Kavaykin A.G., Chichevatov D.A., Gorshenev A.N. (2009) Forecast and prevention of insolvency anastomoses with esophagoplasty // Surgery. (11) 31-33.

11. Wei H.B., Wei B., Zheng Z.H. Zheng F, Qiu WS, et al. (2006) Comparative study on three types of digestive reconstruction after total gastrectomy // Za Zhi..4 (9) 301-304.

12. Birendra K, Ming-Min C, Min Yan (2009) Gastric cancer surgery: Billroth I or Billroth II for distal gastrectomy? // BMC Cancer.No. (9) 28-56.

13. Medzhidov RT, Abdullaeva A.Z, Mamsedova E.P.(2013) The choice of the method of reconstruction of the biliary tract with 
high strictures and "fresh" injuries of the bile ducts // Annals of Surgery. (1) 26-30.

14. Katai H. (1998) The outcame of surgical treatment for gastric carcinoma in the tlderly // Japan J. of Clinical Oncology. (28)112-116.

15. Aujeaky R, Neoral C, Koranda P. (1998) Restoration of digestive passage after total gastrectomy // Rozhl. Chir. (1) 77 $42-44$.

16. Marco B, Gianotti L, Gentilini O. Parisi V, Salis C et al.(2001) Early postoperative enteral nutrition optimized and reduced costs compared with total parenteral nutrition // Crit. Care Med. (29) 242-248

17. McCutcheon A.D.(1968) A fresh approach to the pathogenesis of pancreatitis // Gut.9 (3) 296-310.

18. Moniaux N, Chakraborty S, Yalniz M, Gonzalez J. (2008) Early diagnosis of pancreatic cancer: neutrophil gelatinase-associated lipocalin as a marker of pancreatic intraepithelial neoplasia // Br. J. Cancer. 98 (9)1540-1547.

19. Mutignani M, Tringali A, Shah S.G. V. Perri, P. Familiari et al.(2007) Combined endoscopic stent insertion in malignant biliary and duodenal obstruction // Endoscopy.39 (5)440-447.

20. Alentev S.A, Kotiv B.N, Ivanus S.Ya, Molchanov A.A. Molchanov AA, Usmanov DÉ et al. (2014) Endobiliary stenting with laparoscopic assistance - hybrid technologies in a complex clinical situation. Herald of Surgery.(2) 33-37.

21. Al-Taan O.S. Stephenson J.A, Briggs C, Pollard C.(2010) Laparo-scopic pancreatic surgery: a review of the results and future prospects // HPB (Oxford).12 (4).239-243.

22. Alexakis N, Neoptolemos J.P, Neoptolemos J.P. (2003) Surgery for pancreatic cancer // Update Gastroenterology. Madrid.63-78.

23. Bilimoria K.Y, Bentrem D.J, Lillemoe K.D, Talamonti M.S, Ko C.Y.(2009) Developed by United States Based on Formally Developed Quality Indicators // J. Natl. Cancer Inst..101 (12). 848-859.

24. Li J, Wientjes M.G. (2010) Pancreatic Cancer: Pathobiology, Treatment Options, and Drug Delivery // AAPS J 12 (2). 223232.

25. Nordback I, Sand J, Andren-Sandberg A.(2007) Criteria for alco-holic pancreatitis. Result of an international workshop in tampere Finland // Pancreatology.7.100-104.

26. Hoya Y, Mitsumori N, Yanaga K. (2009) Reconstruction of a distal gastrectomy for gastric cancer // Surg. Today. 39 (8). $647-$ 651.

27. Zherlov G.K.(2005) Clinical endoscopic and morphological criteria for the evaluation of the function of the esophageal anastomoses // Surgery.(7) 9-14.

28. Achkasov E.E, Pugaev A.V, Kharin A.L. (2007) Puncture method in the treatment of postnecrotic cysts of the pancreas // Surgery. (8)33-37.

29. Beger H.G. et al. (2008) Patient heading in 1315 patiens - a monoinstitutionalexperiens // Am. J. Surg. (194)S16 - S19.

30. Yasuda K. (2000)Papillary adenocarcinoma of the stomach // Gastric Cancer. (3) 33-38.

31. Sysolyatin A.A. Chronic pancreatic diseases: a tutorial. Blagoveshchensk: Cupid. state honey. Academy.47-52.
32. Chibisov G.I, Bubnov M, Akhlebinin V.K, Koloskov I.O. (2007) The results of surgical treatment of patients with intestinal colostomy // Coloproctology. 1 P. 23-27.

33. Shalimov A.A, Saenko V.F. (1987) Surgery of the digestive tract. Kiev: Health.568 .

34. Kuzin M.I, Danilov M.V, Blagovidov D.F. (1985) Chronic pancreatitis. M.Medicine,368 .

35. Danilov M.V, Fedorov V.D. (1995)Pancreas Surgery: A Guide for Doctors. M .: Medicine, 512 .

36. Shatverian G.A. (2006) Pancreatoduodenal resection in the treatment of cancer of the pancreatic head and periampular zone: author. dis. Dr. med sciences.29 .

37. Timerbulatov M.V, Gainutdinov FM, Ibatulin A.A. Kulyapin A.V, Khafizov R.M, et al (2011)Experience in the treatment of patients with enterostomy // Kazan Medical Journal.92(1) 124 127.

38. Schneider A, Lohr S, Singer M. (2007)The mi-ANNHEIM of the classifications of the disease // Gastroenterol. (42) 1-19.

39. Yurgelas I.V. (2009)The use of differentiated antimicrobial and nutritive metabolic therapy in the complex treatment of patients with acute perforation mediastinitis: author. dis. Cand. honey. sciences. Voronezh. 28 p.

40. Dantas R.O. (1996) Esophageal motility in patients with esophageal caustic injury // Am. J. Gastroenterol. 91 (6) 1157 1161.

41. Bengmark S. (2003) Modulation of Nutrition and Emergency Nutrition. Nutr. Hosp.18. (1) P. 1-5.

42. Koshel A.P, Mosolkov V.Yu.( 2009)Areflux Yeunostom in surgery of tumor esophageal stenoses // Siberian Journal of Oncology.(3). 33.

43. Luft V.M, Kostyuchenko A.L. (2002) Clinical nutrition in intensive medicine. SPb .: Special literature. $176 \mathrm{p}$.

44. Fedorov V.D.( 2008)Extirpation of the stomach without the application of ezo-phagnoenteroanastomosis with repeated profuse gastric bleeding // Surgery.(3) 4-9.

45. Borodin N.A., Zaitsev E.Yu. (2008)Enteral tube feeding in the treatment of patients with duodenal stump failure / / Questions of nutrition. (5) 41-44.

46. N. Zarechnova. (2006) Experimental and clinical rationale for the integrated use of early enteral nutrition and reamberin in pancreatoduodenal resection: author. dis. Cand. honey. sciences. Saransk. 27 .

47. Piksin I.N.( 2003) Nutritional support in patients with cancer of the esophagus // Parenteral and enteral nutrition: Seventh International Congress. M.73.

48. Buchs N.C, Chilcott M, Poletti P A, Buhler L.H, Morel Ph. (2010) Vascular invasion in pancreatic cancer: imaging modalities, preoperative diagnosis and surgical management // World J. Gastroenterol.16 (7). 818-831.

49. Mosolkov V.Yu.(2011) The rationale and choice of nutritional support in the perioperative period in patients with cancer and post-burn esophageal strictures: auto-ref. dis. Cand. honey. sciences. Tomsk.28 p.

50. Nikoda V.V, Kupriyanov K.Y, Shcherbakova G.N. (2007) Early enteral nutrition after pancreatoduodenal resection // Russian Journal of Gastroenterology, Hepatology, Coloproctology. 17 (4).73-78. 
51. Rasmussen H.H, Holst M., Kondrup J. (2010) Measuring nutritional risk in hospitals // Clin. Epidemiol.No. 2. P. 209216.

(c) (?)

This work is licensed under Creative Commons Attribution 4.0 License

\section{To Submit Your Article Click Here: Submit Manuscript}

DOI: $10.31579 / 2690-8794 / 005$
Ready to submit your research? Choose Auctores and benefit from:

* fast, convenient online submission

* rigorous peer review by experienced research in your field

* rapid publication on acceptance

* authors retain copyrights

* unique DOI for all articles

* Immediate, unrestricted online access

At Auctores, research is always in progress.

Learn more www.auctoresonline.org/journals/clinical-medical-reviews- andreports 